Article

\title{
Which Sectors Really Matter for a Resilient Chinese Economy? A Structural Decomposition Analysis
}

\author{
Xin Mai ${ }^{1}$, Roger C. K. Chan ${ }^{2}$ and Chaoqun Zhan ${ }^{3, *}$ \\ 1 School of Geography, South China Normal University, Guangzhou 510631, China; maixin@m.scnu.edu.cn \\ 2 Department of Urban Planning and Design, The University of Hong Kong, Hong Kong, China; \\ hrxucck@hku.hk \\ 3 Lingnan College, Sun Yat-sen University, Guangzhou 510275, China \\ * Correspondence: zhanchq@mail.sysu.edu.cn
}

Received: 13 October 2019; Accepted: 5 November 2019; Published: 11 November 2019

check for updates

\begin{abstract}
This study explores the structural effect of economic resilience with a case of China by examining the extent to which the major economic sectors contribute to the relative resilience of China's overall economy. By applying a time series analysis, we use the Hodrick-Prescott filter to delineate China's national economy on a quarterly basis and reveal different performances in responding to two recent economic crises in 1997 and 2008. Using quarterly data pertaining to eight economic sectors (including agriculture, industry, and major service sectors) and the national GDP from 1993Q1 to 2017Q2, we examine their effects on China's economic resilience by simulating the responses of the national economy to a unit shock from each sector. Results show that the construction, real estate, and financial services have the greatest potential to "disturb" the national economy whereas the industrial sector has the greatest potential to "stabilize" it. The findings correspond with the understanding that extensive infrastructure development and the real estate boom have driven China's rapid urban development and created economic prosperity, whereas the sectoral decomposition of economic resilience compels a critical reflection on the risks of this growth model.
\end{abstract}

Keywords: economic resilience; sectoral effect; time-series analysis; urbanization; China

\section{Introduction}

An article in The New York Times published in November 2012 [1] advocated for a paradigm shift from an emphasis on sustainability to an emphasis on resilience based on the idea that the latter is a better fit for an imbalanced world. The world is subject to pronounced disruptions and disturbances, and it is contended that the success with which individual countries and international trading bodies negotiate this unpredictable and rugged terrain depends on how resilient they are [2]. The global financial crisis of 2008 and its aftermath had a profound impact on the economies of Western Europe and North America, stimulating extensive studies on the responses to and consequences of recessions [3-7]. The post-crisis economic recovery at multiple geographical scales has given rise to an increasing research attention to the significance, definition, and spatial heterogeneity of resilience, as well as the factors that contribute to achieving and maintaining this state. At the national level, the European countries differed significantly from each other in terms of their responses to the financial crisis of 2008 [8]. Within a specific country, i.e., Canada, resilience literature assessed the importance of industry-mix and regions within the country to account for differences in regional resilience to economic shock [9]. Study about the relationship between regional policies and resilient outcomes examined the ways in which regional policies intersect with exogenous and endogenous factors to explain the relative resilience of various regions with a case of Turkey [10]. To explain resilient performances of urban and regional development, literature has examined the relationship between 
economic resilience and a wide range of factors such as economic structure, labor market conditions, export orientation, innovation, entrepreneurial culture, and institutional arrangements [11]. Among these complex factors, economic structure has been hypothesized as being particularly significant for regional resilience given that economic sectors differ in their reactions to economic shock [12] whereas the relationship between economic structure and resilience remains varied across space.

Compared with the growing body of resilience research in the context of the industrial West, economic resilience has become prominent in both China's official parlance and its popular media. Chinese leaders have openly claimed that China's economy is "highly resilient". For example, at the 2015 Boao Asian Forum, China's President Xi Jinping commented that "the Chinese economy is highly resilient and has much potential, which gives enough room to leverage a host of policy tools". Existing studies of economic resilience have been mainly focused on some specific regions in China such as a study of economic resilience in the Pearl River Delta region [13] and economic resilience of resource-based cities in Northeast China [14]. However, the question of to what extent the Chinese economy as a whole is resilient and what factors contribute to its resilience is still under-researched in the literature. Far from being immune to the global crisis of 2008, China saw the growth of its GDP drop from $14.7 \%$ in 2007 to $8.5 \%$ in 2009 , followed by a decelerated national economy in recent years. Official statements notwithstanding, we know little about how to measure economic resilience in China and the key factors implicated in determining the relative resilience or lack of resilience of the Chinese economy have yet to be identified.

In the present paper, we focus on a structural analysis of economic resilience and examine different roles played by major economic sectors in shaping the national economic resilience. The national economy constitutes an aggregation of multiple sectors such as agriculture, manufacturing, construction, and services. From a structural perspective, economic resilience of this aggregate system is determined by the "system effects", i.e., the effects of interactions among the system's components and the synthetic effects thereby generated [15]. The main objective of this research is to shed light on the endogenous mechanism through which the system's "components" each affect aggregate performances, i.e., the role of major economic sectors in China's resilience to recent global recessions since the establishment of the socialist market economy in 1992. In the present paper, using the quarterly data of China's GDP growth rate and that of eight sectors from 1993Q1 to 2017Q2, we apply vector-auto regression (VAR) modeling and the impulse response function (IRF) to simulate the reaction of the national economy to a sector-specific shock. The national perspective is adopted given that consistent data on the national economy and its sector components are available on a quarterly basis. Equivalent data at the urban or regional level were recorded only on an annual basis, which is not sufficient for time series modeling.

The rest of this paper is organized as follows. First, we present a succinct review of the literature on the determinants of economic resilience in general and the debate about economic structure and resilience in specific. Then, we introduce our research methods including time series modeling and a detrending approach of the Hodrick-Prescott (HP) filter to clean the data. We present our empirical results in the next section and discuss their implications. A summary of major findings and potential areas for future research are given in the closing section.

\section{Economic Resilience and Related Structural Debates}

\subsection{Determinants of Economic Resilience}

These exists a growing number of studies pertaining to the spatial heterogeneity in the impacts of the global financial crisis of 2008 as well as their post-crisis recovery in the industrial West [8,16-20]. The developing literature on economic resilience has indicated that it is a highly complex and multi-dimensional concept and explored the determinants of economic resilience at varied scales [20]. It is argued the extent to which countries are integrated in the global economy, differences in the institutional framework, and differences in sectoral composition are three explanatory factors to the variation in the consequences of the global recession on European countries and regions [21]. 
Factors including economic diversity, trade openness, human and social capital, as well as financial constraints have been considered to explain the geographical asymmetries in economic resilience [22]. At the city level, both individual and place-specific factors account for cities' variation in adaptation and adaptability. Specifically, individual factors accounting for economic resilience include the characteristics of local labor markets, such as gender, age, education, and skill profile of local labor force [18,23-25]. In addition, geographers emphasized "region-specific" or "competitiveness" effects on economic resilience [26]. In this vein of research, literature emphasized the role of place-bound, invisible factors in shaping local economic resilience, such as social values [27], innovation [28], creative small-and-medium sized enterprises (SMEs) [29], entrepreneurship [30,31], as well as the variety of local economic cultures [32]. A recent study identified there exists an inverted U-shaped relationship between local economic embeddedness and resilience [33]. Beyond the socio-economic characteristics, the role of human agency has been found under-explored in understanding the variation in local economic resilience [34]. Taking an agency perspective, insights from this vein of research further emphasized the significance of place and context in resilience studies [34].

\subsection{Economic Structure and Resilience}

Economic structure is considered to be a crucial determinant of economic resilience $[9,26,35]$. To date, studies that address the causal relationship between economic structure and resilience focus on identifying the relative vulnerability of different industries or sectors and sectoral composition in accounting for a given region's ability to withstand a recession. Manufacturing is typically assumed to be a vulnerable sector whereas services are shown to be comparatively more resilient in the Western literature [21,36]. In an empirical study of job losses as a consequence of severe recession from 1987 to 2012 in Canada, it is argued that compared with the business services the manufacturing sector is less resilient to economic shock [9]. Pursuing a finer-scale approach to the subject of resilience to recession, transport equipment was found as the most recession-sensitive of 14 sectors in the EU-wide business cycle [21]. Furthermore, their results confirmed the general view that in comparison with the services sector, manufacturing is more sensitive to economic turbulences. An implication of this sectoral resilience effects for regional development is that regions where manufacturing is dominant are generally expected to be less resilient than regions that rely to a greater extent on service sectors [12]. However, a contradictory finding revealed that the presence of manufacturing activities account for the high resilience of some Italian regions during their recessions and recoveries [37].

In addition, another strand of literature has paid increasing attention on industry portfolios, i.e., how the specific mix of economic activities and the relationships and interdependency between and among them might influence regional reactions to economic shocks $[26,35,38,39]$. In fact, the role of sectoral composition in economic stability has been studied in economic research $[40,41]$ while the focus was placed on exploring whether a diversified economic structure is favorable for regional resilience. However, there is no consensus among economists in regard to the relationship between regional economic diversity and economic stability [42]: Some economists have pointed to industrial diversity as a defining element in explaining a large proportion of regional variation in economic stability $[38,43]$ whereas based on an alternative measurement of regional industrial diversification other scholars have found little evidence to suggest that diversity supports stability [44,45]. In more recent years, urban and regional scholars have argued that a diversified structure helps local economies to absorb sector-specific shocks and thus contributes to overall economic stability. This argument has been supported by empirical studies from Munich and the US according to which a diversified economic structure conditioned the success of each of these countries in riding out the deep recession of $2008[46,47]$. Drawing on the hotly debated relationship between diversity and stability of regional economies, commentators suggested that diversity should not be understood as entailing simply the absence of specialization, especially so among regions or metropolitan areas of sufficient size of their economy [48]. It is further argued that diversification per se may be neutral in its effects on economic stability. The relative vulnerability of a region's economy derives from the extent to which it 
specializes in cyclically sensitive activities. Given the mixed results pertaining to the structural debates of economic resilience, it is essential, therefore, to understand the specific roles played by major sectors in responding to external shocks.

The debate on the divergent roles of different sectors in economic resilience reminds us the relationship between local economic structure and economic resilience may depend on the type of economic shock, as well as how each sector plays its role in responding to the shock, i.e., the endogenous mechanism of how each sector interacts with the aggregate economy for a given region/country and how that composite effect generates resilient outcomes. In this paper, drawing on ideas from the Modern Portfolio Theory (MPT) [49], we argue the existing structural debate on the relative vulnerability of manufacturing or services sector in economic resilience focuses on the unique risk or unsystematic risk which is sector-specific while overlooking the systematic risk that may not be alleviated simply through the diversification strategy. The systematic risk may affect all sectors and thus it is important to understand how different sectors play their role in the aggregate system.

In terms of methodology, a geographical reading of regional economic resilience has typically been done by looking into the spatial heterogeneity in the resistance to and recovery from economic crisis with a spatial econometric model. However, there is no single agreed approach to study economic resilience [26]. A simple way of looking into the relationship between sectoral composition and economic resilience is estimating the crisis sensitivity of different sectors by ordinary least squares (OLS) regression with the observations from different countries [21]. A more advanced method for spatial resilience research is the vector error correction model (VECM), which is used to address permanent effects of employment shocks and the interregional linkages [12,22]. We recognize the significance of spatial dynamics in resilience research while this study focuses on the temporal dimension of economic resilience with a case of China after 1992. With consistent quarterly series data of GDP and that of eight major sectors during the study period, the selected VAR model is used for simulating how the aggregate economy would respond to sector-specific shock, which fits well to the purpose of this study.

This paper contributes to resilience research in two principal aspects. First, given insights from the MPT, we shed light on the relationship between economic structure and regional economic resilience in China by emphasizing that the overall stability of the portfolio depends on the nature of each of its components and the ways in which they interact with the whole system. This perspective is novel in resilience literature and it is more relevant under the Chinese context given that different economic sectors and regions in China have shown uneven extents of integration to the global economy. Therefore, it is imperative for understanding resilience to unravel all aspects of the endogenous mechanism through which an entire system is affected by the distinct components of which it is comprised. Second, the time series analysis adopted in this study followed the evolutionary paradigm of interpreting economic resilience based on its historical information since each variable is regressed on the historical values of its own. This evolutionary thinking is not new in social science research. In studies of urban and regional economic resilience, researchers have long advocated for adopting an evolutionary view in seeking to understand resilience as a process rather than as an outcome [50,51]. However, rigorously interrogating the ways in which historical information has informed resilience remains a challenge. Grounded in evolutionary thinking, this research offers a quantitative method, i.e., the VAR model and IRF simulation from time series analysis, to explain the endogenous mechanism of economic resilience. Though this study is conducted at the national level, the methods applied in this study are applicable to different geographical scales given the availability of data.

Nevertheless, economic structure provides only a partial explanation for regional economic resilience. It is found that regional-specific effects appear to have played a significant role on a par with that of economic structure in shaping the resistance and recoverability of major UK regions to four significant recessions over the last 40 years [26]. However, a full explanation of China's economic resilience is far beyond the scope of this paper. Instead, we focus on the structural aspect and aim to open the black box of how the national economy reacts to turbulence from each of its major components. 
Yet, our research goes beyond the conventional structural debate of diversity and resilience given that a national economy is necessarily diversified. Rather than arguing which sector is more vulnerable to economic shock, we contend that it is critical to understand the specific roles of major sectors in shaping the aggregate economic resilience, which necessities explicating the endogenous mechanism whereby major economic sectors interact with the overall economy.

\section{Research Methods}

\subsection{Measurement Issues}

Measuring economic resilience in China has to address a few specific concerns. First, the study period of economic resilience in China is shorter than that of the West. China's annual GDP growth rate from 1953 to 2015 shows a salient trend of increasing stability (Figure 1). Absolute declines in the GDP can be seen pre-1976 only, i.e., during the Maoist era when resource allocation in China and thus economic growth were strictly under the control of the state. The discussion of economic resilience is invalid during the period of a command economy. Therefore, we examined China's economic resilience after 1992 since it was not until 1992 that China's socialist market economy was formally established. Since then, the hybrid effects of the state and the market have complicated the forces behind economic fluctuations. Second, a finer-scale approach of investigation on China's economic growth is in order since the annual data indicate that neither the Asian financial crisis of 1997 nor the global financial crisis of 2008 had more than a very weak negative impact on the Chinese economy as shown in Figure 1. Given a shorter period of observation, a closer look at economic fluctuations in China on a quarterly basis is necessary to reveal the processes through which the country responded to any economic shocks identified. Third, compared with the Western literature about investigating the absolute decline and recovery of employment, exploring economic resilience in China has to be considered in reference to the fluctuation of the growth rate in relative terms. We used data of economic output (measured by GDP) rather than employment to conduct a longitudinal study of economic resilience in China. Employment used to be the preferred indicator for studying economic resilience in Western literature $[18,20,22,35,37]$ whereas China's official statistical records of employment is not sensitive to economic fluctuations. More accurately, China's urban unemployment has been highly underestimated in official data given the problematic definition, data collection system, and calculation of "registered urban unemployment" from the Chinese National Bureau of Statistics (hereafter NBS) (see detailed discussion from prior research [52]). The exclusion of laid-off (xiagang) workers and unemployed persons without urban resident status (hukou), i.e., rural migrants, seriously reduced the data credibility of Chinese unemployment rate. Under the urban-rural dual economy, a large number of migrant workers from rural to urban areas are not fully counted in official statistics. When the economy declines, they are in the most vulnerable position to lose jobs, although this is hardly reflected in statistical data. In addition, the Chinese state-owned enterprises (SOEs) used to maintain life tenure with their employees in the past. The soft-budget constraints enable the SOEs to achieve that commitment, and even under difficult times, the SOEs would not lay off their workers. Despite the continuous restructuring of the Chinese SOEs, the institutional inertia still takes effect. As a result, official data of employment (or unemployment) is hardly reliable for assessing resilience. Comparatively, output data is consistently available over time, which is deemed an appropriate variable to study economic resilience under the Chinese context. 


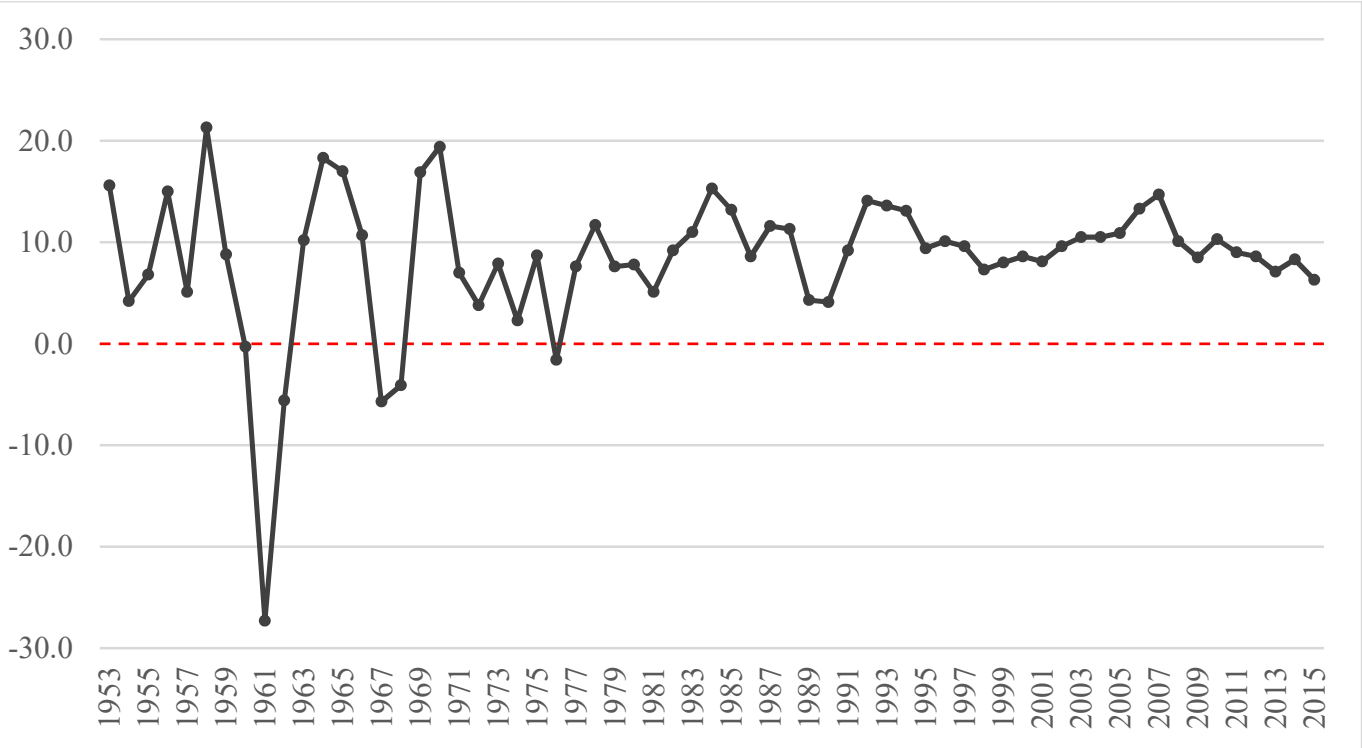

Figure 1. China's annual GDP growth rate from 1953 to 2015. (Source: Data from China Statistical Yearbook (2016).)

\subsection{Seasonal Adjustment and Hodrick-Prescott Filter}

For the present paper, a longitudinal observation of economic resilience in China was undertaken in reference to the post-reform period with quarterly data of GDP growth rate from 1993Q1 to 2017Q2. Using quarterly data, we used the standard U.S. Census Bureau's X12 seasonal adjustment program from EViews 10 to adjust for the potential seasonal trends in our series. The seasonally adjusted data were saved as *_sa. We de-trended the quarterly GDP growth rate of China and that of eight major economic sectors with the HP filter to separate fluctuations in economic growth from its long-term trend [53]. The HP filter is a frequently used tool in Real Business Cycle (RBC) theory to decompose a time series into its growth and cyclical components [54]. According to the rationale of HP filter [55], a given time series the growth rate of $G D P_{t}$ is the sum of a growth component $g_{t}$ and a cyclical component $c_{t}$ expressed as

$$
G D P_{t}=g_{t}+c_{t} \quad(t=1,2, \ldots, T) .
$$

The growth component measures the long-term trend or the potential output, and the cyclical component indicates the output gap between the real and potential output. The logarithm of the HP filter is given by

$$
\operatorname{Min}\left\{\sum_{t=1}^{T}\left(G D P_{t}-g_{t}\right)^{2}+\lambda \sum_{t=1}^{T}\left[\left(g_{t}-g_{t-1}\right)-\left(g_{t-1}-g_{t-2}\right)\right]^{2}\right\},
$$

where $G D P_{t}$ is the raw data of the growth rate of GDP, and $g_{t}$ represents the trend component. The first part of the equation is the sum of the squared cyclical component. The second part of the equation is $\lambda$ multiplied by the sum of squares of the growth component's second differences. The smoothing parameter $\lambda$ penalizes the variability in the growth component series [55]. The standard practice in the econometrics is to set $\lambda$ as 1600 for quarterly data as we applied in this study.

Economic resilience is assessed by observing the change of cyclical component of quarterly GDP growth rate. The filtering approach extracted the long-term trend component of the GDP growth rate, leaving the cyclical component which centers on zero. A negative cyclical component indicates that the real output is smaller than the potential output, implying production resources have not been fully utilized in the society. When the economy was shocked, the gap between real and potential output would normally enlarge. Economic resilience is revealed if the cyclical component could quickly bounce back to or even beyond zero. In that case, idle factory buildings, equipment, and labor force 
are reused to realize the full potential of social production capabilities, meaning that the economy has recovered from the shock.

Besides the national GDP, we selected the quarterly growth rate of eight sectors during the same study period to investigate their interactions with the national economy. The eight sectors included in this study are (1) agriculture (2) industry (industry sector includes mining, manufacturing, and the production and supply of electronic power and heat power according to the "Industry Classification of the National Economy (GB/T 4754-2011)", manufacturing is the dominant sector); (3) construction; (4) retailing; (5) transport, storage, and post (referred to as transport); (6) hotel and catering services (referred to as hotel and catering); (7) financial services and (8) real estate. The sources of the annual GDP growth rate since 1953 are China Statistical Yearbook 2016, 60 Years of New China [56], and the China Compendium of Statistics 1949-2008 [57], all published by NBS of China. We retrieved time series data for the sectoral GDP growth rate for 1993Q1 to 2017Q2 from the official NBS database. All the data are calculated at constant prices.

\subsection{Stationarity Test and the VAR Model}

Our data set contains the cyclical component of quarterly GDP growth rate and that of eight major sectors during the study period. The stationarity of the data series should be tested before developing the VAR model. The Augmented Dickey-Fuller (ADF) test, being one of the unit root tests used in statistics and econometrics, was adopted to test the stationarity of all those time series data. The principle of the unit root test is to testify whether the latent roots fall within a unit cycle. If all of the latent roots are within a unit cycle, it means the time series data are stationary; otherwise, any latent root falls on or outside of the unit cycle indicates that the series is non-stationary. The ADF tests were conducted by EViews 10.

Then, we developed a VAR model via a time series analysis - an approach based on the evolutionary thinking that past data pertaining to a variable can be used to forecast its development. There are only endogenous variables in a VAR model, each of which are predicted evolutionarily based on its own lagged values and the lags of the other variables. For a time series data GDP growth rate $\left\{g d p R_{t}\right\}$, the value of variable $g d p R$ at the time $t$ can be regressed on the historical values of its own, which is given by the auto-regression model $(A R)$. The standard $p$-order $A R$ model is given as

$$
A R(p): g d p R_{t}=\phi_{1} g d p R_{t-1}+\phi_{2} g d p R_{t-2}+\ldots+\phi_{p} g d p R_{t-p}+\varepsilon_{t},
$$

where $g d p R_{t-p}$ denotes $p$-periods lagged $g d p R_{t}$. Multiple time series analysis extends the idea of evolution to a set of time series variables. The primary model in multivariate time-series analysis is the VAR model, which studies the linear inter-dependencies among multiple time series. A stable VAR model of $p$-order is given as [58]

$$
g d p R_{t}=v+\mathrm{A}_{1} g d p R_{t-1}+\mathrm{A}_{2} g d p R_{t-2}+\ldots+\mathrm{A}_{p} g d p R_{t-p}+\mu_{t}, \quad(t=1, \ldots, T),
$$

where $g d p R_{t}=\left(g d p R_{\mathrm{N} t}, g d p R_{\mathrm{Agr}_{t}}, \ldots, g d p R_{R E_{t}}\right)^{\prime}$ denote a $(n \times 1)$ vector of the cyclical component of GDP growth rate of the nation and each sector. $\mathrm{A}_{i}$ are $(n \times n)$ coefficient matrices and $v=\left(v_{1}, \ldots, v_{n}\right)^{\prime}$ is a fixed $(n \times 1)$ vector of intercept terms. $\mu_{t}=\left(\mu_{1 t}, \ldots, \mu_{n t}\right)^{\prime}$ is a $(n \times 1)$ white noise vector process satisfying the conditions of $E\left(\mu_{t}\right)=0, E\left(\mu_{t} \mu_{t}^{\prime}\right)=\sum_{\mu}$ and $E\left(\mu_{t} \mu_{t}^{\prime}\right)=0$ for $s \neq t$.

Based on the above VAR model, we applied an IRF simulation and variance decomposition (VD) to identify the sectors that contribute most to China's economic resilience. The IRF can simulate the impacts of unexpected shocks to a specified variable on the variables in the model, which is useful in capturing the model's dynamic properties. The rationale behind the IRF is that for multiple time series, a shock to one series generates an immediate effect on that same series, and it can also affect other variables in a system, which can, in turn, affect the original variable. The results of the IRF 
simulation delineate the national economy's responses to a unit shock from each sector, thus unfolding the endogenous mechanism of national economic turbulence.

\section{Empirical Results}

\subsection{A Holistic Observation of China's Relative Economic Resilience in Response to Two Recent Shocks}

At the aggregate level, filtering result of the seasonal adjusted GDP growth rate of China from 1993Q1 to 2017Q2 is shown in Figure 2. The trend curve shows a significant decrease in the late 1990s and after 2008. However, the cycle curve shows a minor decline in the late 1990s compared with a sharp decline in 2008. We used the cyclical component of the GDP growth rate to measure China's economic resilience and the result reveals different resilience of China's national economy in responding to two recent economic crises in 1997 and 2008.

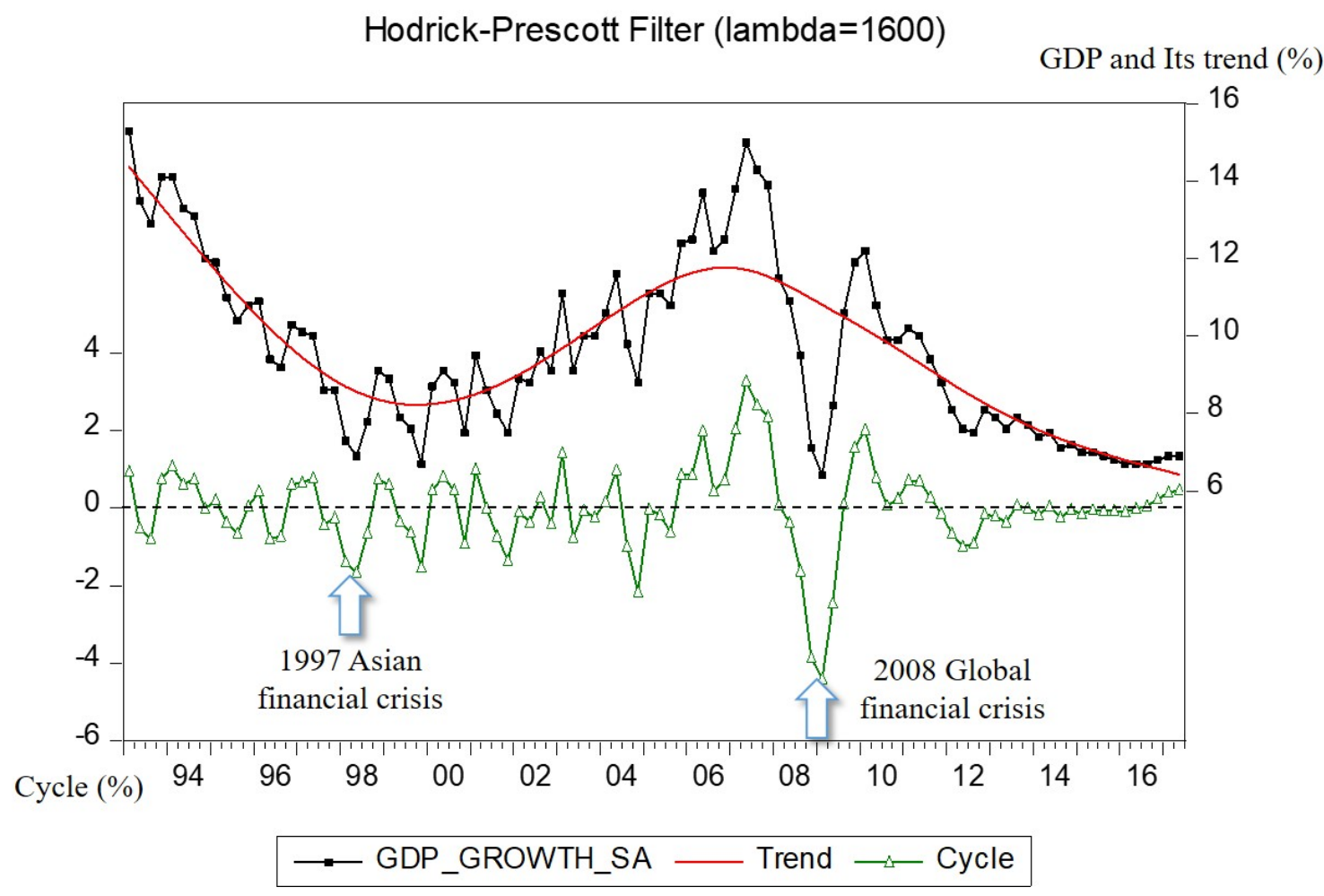

Figure 2. Hodrick-Prescott (HP) filter of China's quarterly GDP growth rate (1993Q1-2017Q2).

The financial crises of 1997 and 2008 each had a direct negative impact on China's economy by decreasing external demand. However, the circumstances in which that impact occurred differed significantly between these two crisis events. Ushered in by its formal endorsement of a socialist market economy in 1992, China experienced a rapid economic expansion, with an average growth rate of $13.6 \%$ from 1992 to 1994 . However, there was also a high rate of inflation in China during the same period, reaching an unprecedented level of $24.1 \%$ in 1994 [59]. To cool down the overheated economy, Zhu Rongji, China's prime minister at the time, implemented an austerity program before the crisis of 1997, leading to a downward trend in potential output (Figure 2). The cycle curve did not show a prominent deviation from zero in 1997, revealing that the consequence of the 1997 Asian financial crisis was not severe in comparison with the crisis of 2008. After 1997, China experienced economic expansion over about 10 years as illustrated by the upward trend curve. China's national economic growth rate reached its peak level of $14.7 \%$ in 2007, just before the global financial crisis of 2008. Shocked by the 2008 crisis, the cyclical component of the country's quarterly GDP growth rate underwent a sharp decline, implying that the real output of the Chinese economy fell far short of the level that would have been projected otherwise. 


\subsection{Sectoral Decomposition of China's Economic Resilience}

Having the data set of the cyclical component of each sector from 1993Q1 to 2017Q2, the Pearson correlations of each pairwise variable were calculated via SPSS (Table 1). The results show that the industry (coefficient of 0.897 ) and real estate (coefficient of 0.588 ) sectors are strongly correlated with the cyclical movement of the Chinese economy. Industry, with manufacturing as its major component, shows the highest correlation coefficient with the national economy. Next, transport and retailing show moderate correlations with the national economy, with coefficients of 0.433 and 0.406 , respectively. The inter-sectoral correlations reveal that the real estate sector has statistically significant correlations with five of the other eight variables: aggregate GDP (0.588), financial services (0.448), construction (0.386), industry (0.383), and retailing (0.305). The financial services sector is also closely related with the aggregate GDP, real estate, retailing, and construction sectors. Given that both the transport and real estate sectors are major consumers of manufacturing products, the second most relevant sector for industry is transport (the coefficient for this latter sector is 0.396 in the third column), followed by industry and real estate with a coefficient of 0.383 . Findings on the relevance of the cyclical component of each sector and that of the national economy reveal that the significance of different sectors to the aggregate resilience is not just a matter of the sectoral proportion in the national economy. Though industry accounted for 33.3\% of the national economy in 2016, the proportion of real estate sector in the national economy was only $6.5 \%$ in 2016 [60]. Nevertheless, these two sectors have shown the highest correlations with the national economic fluctuations. Given this, we further developed a VAR model to explore the endogenous mechanism of the sectoral effects. 
Table 1. Pearson correlations between the pairwise cyclical components of the major sectors.

\begin{tabular}{|c|c|c|c|c|c|c|c|c|c|}
\hline & Cycle GDP & Cycle AGR. & Cycle IND. & Cycle CON. & Cycle RET. & Cycle TRA. & Cycle HOT. & Cycle FIN. & Cycle R.E \\
\hline Cycle GDP & 1 & & & & & & & & \\
\hline Cycle Agriculture & -0.222 * & 1 & & & & & & & \\
\hline Cycle Industry & $0.897^{* *}$ & $-0.286^{* *}$ & 1 & & & & & & \\
\hline Cycle Construction & 0.189 & -0.125 & 0.010 & 1 & & & & & \\
\hline Cycle Retailing & $0.406^{* *}$ & -0.124 & 0.253 * & 0.138 & 1 & & & & \\
\hline Cycle Transport & $0.433^{* *}$ & 0.116 & $0.396^{* *}$ & -0.179 & -0.031 & 1 & & & \\
\hline Cycle Hotel and catering & 0.129 & -0.124 & $0.209 *$ & -0.133 & 0.177 & -0.086 & 1 & & \\
\hline Cycle Financial Services & $0.400 * *$ & -0.142 & 0.150 & $0.344^{* *}$ & $0.370 * *$ & -0.183 & -0.141 & 1 & \\
\hline Cycle Real Estate & $0.588^{* *}$ & $-0.424^{* *}$ & $0.383 * *$ & $0.386^{* *}$ & $0.305 * *$ & 0.119 & 0.002 & $0.448^{* *}$ & 1 \\
\hline
\end{tabular}

*. Correlation is significant at the 0.05 level (two-tailed). ${ }^{* *}$. Correlation is significant at the 0.01 level (two-tailed). 
The stationarity of each time series was tested via ADF tests (Table 2). Each data series passed the stationary test, as the cyclical component of each sector's growth rate had already been filtered without trend or seasonal impact. Therefore, the raw data for each variable were used to develop the VAR model.

Table 2. Stationarity results of the Augmented Dickey-Fuller (ADF) tests for each time series.

\begin{tabular}{ccccc}
\hline & Test Format & $t$-Statistic & $p$ Value & Result \\
\hline GDP & $\mathrm{N}, \mathrm{N}, 1$ & -5.237903 & $0.0000^{*}$ & Stationary \\
Agriculture & $\mathrm{N}, \mathrm{N}, 0$ & -5.233866 & $0.0000^{*}$ & Stationary \\
Industry & $\mathrm{N}, \mathrm{N}, 2$ & -6.158719 & $0.0000^{*}$ & Stationary \\
Construction & $\mathrm{N}, \mathrm{N}, 0$ & -5.630373 & $0.0000^{*}$ & Stationary \\
Retailing & $\mathrm{N}, \mathrm{N}, 0$ & -5.738462 & $0.0000^{*}$ & Stationary \\
Transport & $\mathrm{N}, \mathrm{N}, 0$ & -5.585702 & $0.0000^{*}$ & Stationary \\
Hotel and catering & $\mathrm{N}, \mathrm{N}, 0$ & -5.056096 & $0.0000^{*}$ & Stationary \\
Financial services & $\mathrm{N}, \mathrm{N}, 0$ & -3.936282 & $0.0001^{*}$ & Stationary \\
Real Estate & $\mathrm{N}, \mathrm{N}, 2$ & -6.683200 & $0.0000^{*}$ & Stationary \\
\hline
\end{tabular}

Note: * indicates a significance level of $1 \%$.

The results of the IRF simulation are graphically presented in Figure 3. Within the observation of 15 periods, the responses of the cyclical component of the GDP growth rate to the sectoral shocks finally approached zero. The cyclical component of the GDP growth rate is highly sensitive to a unit shock from each of the construction, real estate, and financial services sectors. Despite a short lag, the response to the shock from the construction sector was the most significant and persistent of all the sectors considered herein. It increased to the highest level of 0.29 in the fourth period and remained positive in the first six periods. The national economy responded to the real estate and financial services sectors more promptly whereas the extent of the reaction was not as strong as that of the construction sector. As shown in the bottom two graphs of Figure 3, response of the national economy to a unit shock from the financial services sector reached its peak level of 0.21 in the secondary period, and then decreased steadily and became negative in the seventh period. In comparison, the reaction of the national economy to real estate disturbances was 0.18 in the secondary period and increased further to 0.23 in the third period. It dropped below zero in the sixth period and finally faded out after the tenth period.

Findings from the variance decomposition (VD) reveal similar sectoral effects to those shown by the IRF simulation (as shown in Table 3). After 15 periods, the fluctuation of the GDP growth rate itself explained only $44.14 \%$ of its total variance, whereas the construction and real estate sectors accounted for $16.33 \%$ and $9.63 \%$, respectively. These sectors are followed by the agriculture and financial services sectors, which explain $7.15 \%$ and $7.12 \%$, respectively, of the total variation. The industry sector accounted for only $6.94 \%$ of the total variance. The result of VD confirmed that construction and real estate sectors have contributed the most to the variance of China's national economy despite their relative small size in the overall "portfolio".

The IRF simulation and VD unfolded the endogenous structure of China's relative economic resilience. According to the response patterns (Figure 3), the effects of each of eight sectors on China's economic resilience can be understood as follows: first, the results of the IRF simulation verify the potential role of the construction, real estate, and financial services sectors in "disturbing" the national economy. A unit shock, i.e., an impulse from one of these sectors would generate significant impact on the national economy. Second, the response pattern is almost reversed in the cases of agriculture and industry, which have served as "stabilizers" for the overall economy. There is a negative deviation of the national economy followed by positive responses to a unit shock from the agriculture and industry sectors, as the first two graphics of Figure 3 show. Finally, we observe that the shocks from retailing, transport, as well as hotel and catering do not have a strong impact on the national economy. 
Response of GDP_SA to AGRICULTURE_SA

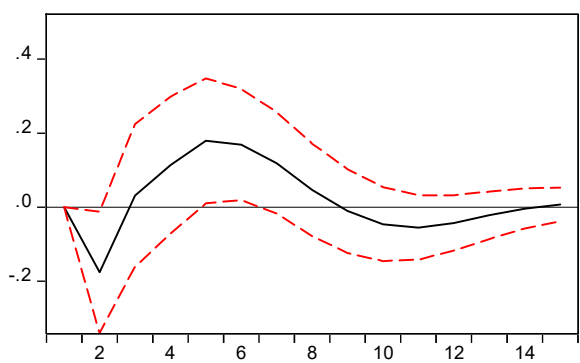

Response of GDP_SA to CONSTRUCTION_SA

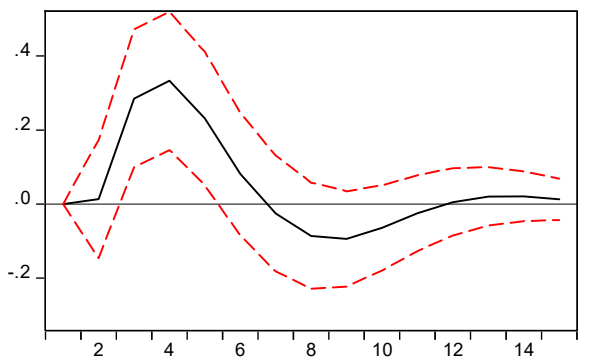

Response of GDP_SA to TRANSPORT_SA

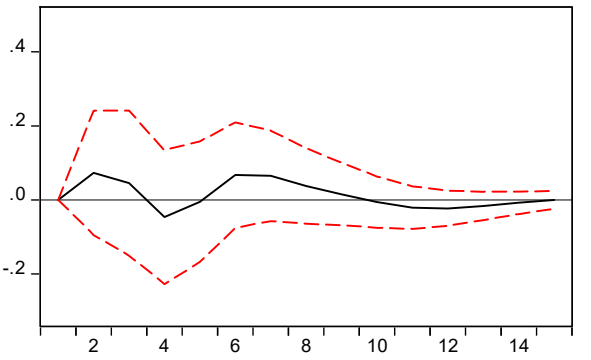

Response of GDP_SA to FNANCE_SA

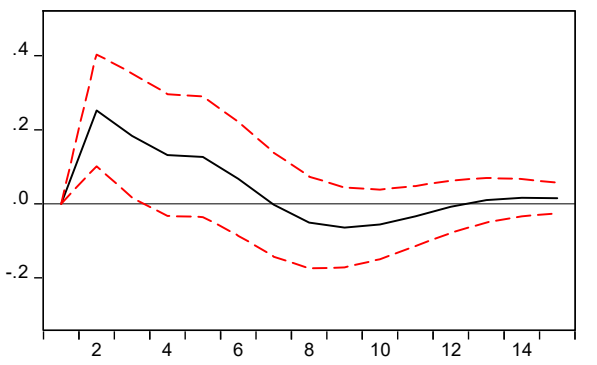

Response of GDP_SA to INDUSTRY_SA

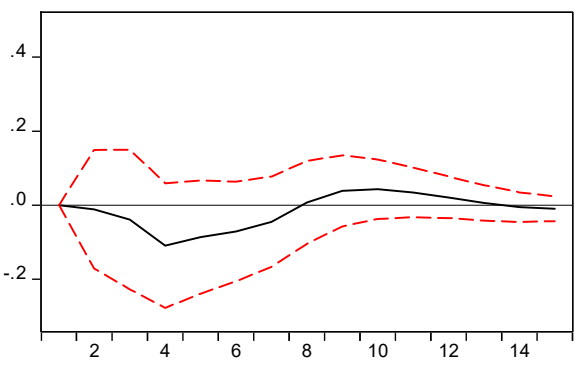

Response of GDP_SA to RETAILING_SA

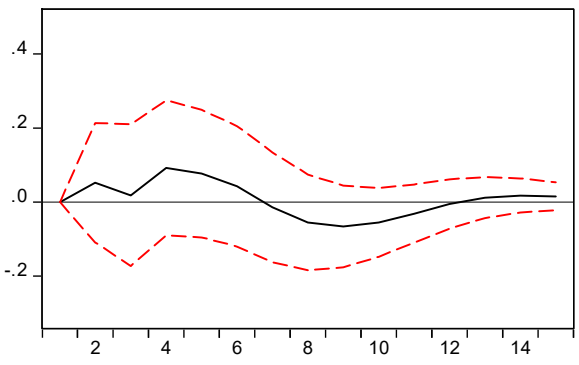

Response of GDP_SA to HOTEL_SA

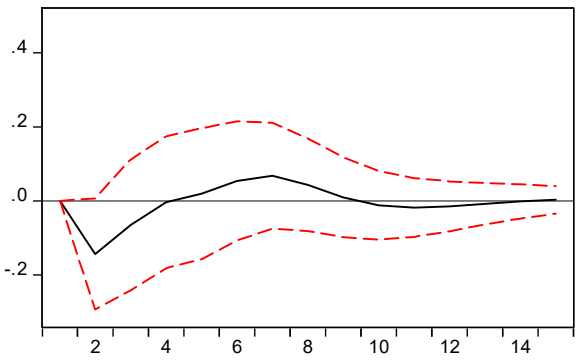

Response of GDP_SA to REALESTATE_SA

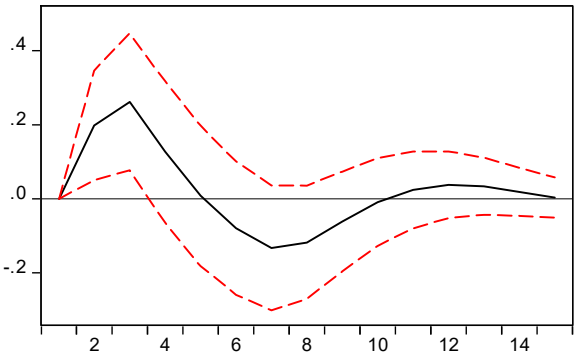

Figure 3. Results of the impulse response function (IRF) simulation. 
Table 3. Variance decomposition of the cyclical component of China's GDP growth rate.

\begin{tabular}{ccccccccccc}
\hline Period & S.E. & GDP & AGR. & IND. & CON. & RET. & TRA. & HOT. & FIN. & R.E. \\
\hline 1 & 0.59 & 100.00 & 0.00 & 0.00 & 0.00 & 0.00 & 0.00 & 0.00 & 0.00 & 0.00 \\
2 & 0.82 & 79.81 & 1.55 & 5.02 & 0.50 & 0.05 & 0.00 & 1.58 & 6.61 & 4.88 \\
3 & 0.95 & 64.46 & 1.73 & 6.03 & 8.95 & 0.13 & 0.11 & 1.94 & 6.47 & 9.14 \\
4 & 1.03 & 55.29 & 1.47 & 7.01 & 15.35 & 0.53 & 0.64 & 1.78 & 6.97 & 9.01 \\
5 & 1.08 & 51.46 & 2.00 & 7.13 & 17.70 & 1.17 & 0.59 & 1.64 & 7.55 & 8.40 \\
6 & 1.11 & 50.09 & 3.40 & 6.87 & 17.66 & 1.44 & 0.92 & 1.60 & 7.27 & 8.31 \\
7 & 1.14 & 48.62 & 5.19 & 6.50 & 16.72 & 1.39 & 1.40 & 1.73 & 6.91 & 9.20 \\
8 & 1.17 & 47.08 & 6.23 & 6.39 & 16.40 & 1.39 & 1.90 & 1.82 & 6.86 & 9.67 \\
9 & 1.18 & 45.95 & 6.37 & 6.57 & 16.53 & 1.65 & 2.13 & 1.83 & 7.05 & 9.64 \\
10 & 1.19 & 45.29 & 6.28 & 6.83 & 16.65 & 2.00 & 2.13 & 1.82 & 7.19 & 9.51 \\
11 & 1.20 & 44.89 & 6.41 & 6.97 & 16.58 & 2.21 & 2.12 & 1.80 & 7.19 & 9.51 \\
12 & 1.20 & 44.57 & 6.74 & 6.99 & 16.45 & 2.26 & 2.18 & 1.78 & 7.13 & 9.60 \\
13 & 1.21 & 44.34 & 7.01 & 6.96 & 16.36 & 2.25 & 2.27 & 1.77 & 7.10 & 9.65 \\
14 & 1.21 & 44.20 & 7.13 & 6.93 & 16.33 & 2.25 & 2.32 & 1.77 & 7.11 & 9.64 \\
15 & 1.21 & 44.14 & 7.15 & 6.94 & 16.33 & 2.27 & 2.34 & 1.77 & 7.12 & 9.63
\end{tabular}

Note. AGR. = Agriculture, IND. = Industry, CON. = Construction, RET. = Retailing, TRA. = Transport, HOT. = Hotel and catering, FIN. $=$ Financial services, R.E. $=$ Real Estate

Results of the time series analysis indicate that a heavy reliance on the construction, real estate, and financial services sectors may increase the endogenous vulnerability of the national economy from a resilience perspective. China's economic "miracle," in large measure, has been achieved by enormous investment in the production and reproduction of urban space over the last 40 years. Urbanization, in terms of "fixing" capital in the urban space, is of paramount importance to China's economic growth. China's industrial and urban development was characterized by development zone fever and real estate fever over the last four decades. In more recent years, the bidding war over hosting mega-events and a feverish implementation of mega-projects among Chinese cities and regions are strong evidence of local governments' interest in reproducing space and marketing place in order to sustain resilient economic growth [61]. However, the simulation results of the sectoral effects on China's economic resilience indicate that the national economy would be highly sensitive to unpredicted shock from construction, real estate, and financial services sectors. Though the identified critical sectors remain the major sectors receiving enormous investments in contemporary China (such as the four-trillion-yuan (equivalent to $\$ 585.5$ billion) stimulus package fueled by the Chinese governments in 2009), this study raises a serious concern that any considerable reduction of investment in these sectors would challenge the stability of the national economy to a greater extent than would be the case for a reduction in any of the other sectors. Therefore, our analysis calls for a critical reflection on the potential risk of "fixing" capital in the built environment as a way to counterbalance the adverse effects of an economic slowdown. Given uncertainty for the continuity of large-scaled investment in these three critical sectors, it is imperative to ask what the other source of national economic resilience in the future would be.

\section{Conclusions}

This research addresses the structural discourse of economic resilience from a novel perspective with insights from the portfolio theory. The relationship between economic structure and resilience has long been recognized while the scholarship to date focuses on the vulnerability of specific sectors. In the Western literature, manufacturing has been deemed the most vulnerable sector in terms of failing to withstand economic turbulence whereas the services have generally been considered capable of absorbing recessionary shocks $[9,36]$. However, we contend the vulnerability of manufacturing or services sector is subject to specific shock which can be understood as responses to a unique risk or unsystematic risk. In addition to sector-specific shock, there exists systematic risk which may generate impacts on all components of the system, and such impacts could hardly be mitigated simply 
through diversifying the structure of the given system. Thus, insights from the MPT reminds us diversification may not be helpful in cushioning systematic risk. Rather than seeking the most "safe" portfolio composed of selected "ideal" types of economic sectors, it may be more helpful to understand what are the roles played by each sector under different local contexts so as to generate targeted policies. Resilience study should not replicate the common mistake made in the previous study of competitiveness, that is, identifying determinants of urban competitiveness as being insensitive to contingencies of place [5]. It may never be taken for granted that the same drivers of change are at work everywhere and once the right levers have been pulled, the appropriate drivers will respond and deliver required outcomes.

In this paper, we argue that study of economic resilience should pay more attention on the ways in which different sectors intersect with each other and how that internal interactions generate resilient outcomes of a given country's economy overall. Our analysis extended the structural discourse of economic resilience research beyond the proportional distribution of the components of China's economy, such as the debate over diversification versus specialization. Instead, we demonstrated that insights of greater significance can be gained by identifying the role of each sector in determining the extent of a country's, in this case, China's, aggregate resilience. As stated, our goal in this paper was to open the black box of the national economy's responses to turbulence experienced by each of its principal components by applying a VAR model and IRF simulation based on quarterly data of China's GDP growth rate and that of eight major sectors for the 1993Q1-2017Q2 period. The adopted method of IRF simulates the reactions of the cyclical fluctuation of the GDP growth rate to a unit shock, i.e., an impulse from one specific sector. The simulation results showed that if subjected to an economic shock that construction, real estate, and financial services sectors have the greatest potential to disturb the national economy. However, we also showed that the industry sector (dominated by manufacturing) is capable of absorbing external shocks and, therefore, served as a stabilizing factor in the national economy. Investment in the built environment, as we witnessed an unprecedented speed of infrastructure development and urbanization in China, has made a considerable contribution to the prosperity and resilience of the Chinese economy. However, findings of this study call for a critical reflection on the risk of this growth model.

This study has a number of limitations. First, though we examined China's responses to the two major external shocks from the crises of 1997 and 2008, the structural decomposition analysis of China's economic resilience was based on a long-term observation since 1993. Impacts of these economic crises on China's economy have been embedded in the evolution of the cyclical fluctuation of the national economy and its sectoral components. Second, this study did not take China's spatial inequality at the sub-national level into consideration. The ways in which major sectors take effect may differ significantly across the space. Future study may address the limitation at the regional level with available data. As stated, the structural discourse of economic resilience should go beyond asking which sector is the most resilient one, if it exists. More insights would be gained through a deeper understanding of how different sectors played their role in the aggregate economy, which is highly contingent on region and place.

Author Contributions: Conceptualization, X.M., R.C.K.C. and C.Z.; methodology, X.M. and C.Z.; software X.M.; validation R.C.K.C. and C.Z.; formal analysis, X.M. and R.C.K.C.; investigation, X.M.; data curation, X.M.; writing-original draft preparation, X.M., R.C.K.C. and C.Z.; writing—review and editing, X.M. and C.Z.; funding acquisition, X.M. and C.Z.

Funding: This research was funded by the China Postdoctoral Science Foundation Grant [grant number 2019M652933] and the China Postdoctoral Science Foundation Grant [grant number 2019T120759].

Acknowledgments: The authors are grateful to the constructive comments from two anonymous reviewers. Any errors and misinterpretations remain the authors'.

Conflicts of Interest: The authors declare no conflict of interest. 


\section{References}

1. The New York Times, 2 November 2012. Forget Sustainability. It's About Resilience: Learning to Bounce Back. The Opinion Pages of The New York Times. Available online: http://www.nytimes.com/2012/11/03/ opinion/forget-sustainability-its-about-resilience.html (accessed on 11 November 2019).

2. Zolli, A.; Healy, A.M. Resilience: Why Things Bounce Back; Simon and Schuster: New York, NY, USA, 2013.

3. Bailey, D.; De Propris, L. Recession, recovery and resilience? Reg. Stud. 2014, 48, 1757-1760. [CrossRef]

4. Cellini, R.; Torrisi, G. Regional resilience in Italy: A very long-run analysis. Reg. Stud. 2014, 48, $1779-1796$. [CrossRef]

5. Christopherson, S.; Michie, J.; Tyler, P. Regional resilience: Theoretical and empirical perspectives. Camb. J. Reg. 2010, 3, 3-10. [CrossRef]

6. Modica, M.; Reggiani, A. Spatial economic resilience: Overview and perspectives. Netw. Spat. Econ. 2015, 15, 211-233. [CrossRef]

7. Pike, A.; Dawley, S.; Tomaney, J. Resilience, adaptation and adaptability. Camb. J. Reg. 2010, 3, 59-70. [CrossRef]

8. Cuadrado-Roura, J.R.; Martin, R.; Rodríguez-Pose, A. The economic crisis in Europe: Urban and regional consequences. Camb. J. Reg. 2016, 9, 3-11. [CrossRef]

9. Ray, D.M.; MacLachlan, I.; Lamarche, R.; Srinath, K.P. Economic shock and regional resilience: Continuity and change in Canada's regional employment structure, 1987-2012. Environ. Plan. A 2016, 49, 952-973. [CrossRef]

10. Eraydin, A. The role of regional policies along with the external and endogenous factors in the resilience of regions. Camb. J. Reg. 2015, 9, 217-234. [CrossRef]

11. Martin, R.; Sunley, P. On the notion of regional economic resilience: Conceptualization and explanation. J. Econ. Geogr. 2015, 15, 1-42. [CrossRef]

12. Fingleton, B.; Garretsen, H.; Martin, R. Recessionary shocks and regional employment: Evidence on the resilience of UK regions. J. Reg. Sci. 2012, 52, 109-133. [CrossRef]

13. Du, Z.; Zhang, H.; Ye, Y.; Jin, L.; Xu, Q. Urban shrinkage and growth: Measurement and determinants of economic resilience in the Pearl River Delta. J. Geogr. Sci. 2019, 29, 1331-1345. [CrossRef]

14. Tan, J.; Zhang, P.; Lo, K.; Li, J.; Liu, S. Conceptualizing and measuring economic resilience of resource-based cities: Case study of Northeast China. Chin. Geogr. Sci. 2017, 27, 471-481. [CrossRef]

15. Béné, C.; Wood, R.G.; Newsham, A.; Davies, M. Resilience: New utopia or new tyranny? Reflection about the potentials and limits of the concept of resilience in relation to vulnerability reduction programmes. IDS Work. Pap. 2012, 2012, 1-61. [CrossRef]

16. Bristow, G.I.; Healy, A.; Norris, L.; Wink, R.; Kafkalas, G.; Kakderi, C.; Espenberg, K.; Varblane, U.; Sepp, V.; Sagan, I.; et al. ECR2. Economic Crisis: Regional Economic Resilience; Project Report; ESPON: Brussels, Belguim, 2014; 110p.

17. Davies, S. Regional resilience in the 2008-2010 downturn: Comparative evidence from European countries. Camb. J. Reg. Econ. Soc. 2011, 4, 369-382. [CrossRef]

18. Doran, J.; Fingleton, B. Employment resilience in Europe and the 2008 economic crisis: Insights from micro-level data. Reg. Stud. 2016, 50, 644-656. [CrossRef]

19. Dubé, J.; PolèSe, M. Resilience revisited: Assessing the impact of the 2007-09 recession on 83 Canadian regions with accompanying thoughts on an elusive concept. Reg. Stud. 2016, 50, 615-628. [CrossRef]

20. Sensier, M.; Bristow, G.; Healy, A. Measuring regional economic resilience across Europe: Operationalizing a complex concept. Spat. Econ. Anal. 2016, 11, 128-151. [CrossRef]

21. Groot, S.P.; Möhlmann, J.L.; Garretsen, J.H.; de Groot, H.L. The crisis sensitivity of European countries and regions: Stylized facts and spatial heterogeneity. Camb. J. Reg. 2011, 4, 437-456. [CrossRef]

22. Di Caro, P. Testing and explaining economic resilience with an application to Italian regions. Pap. Reg. Sci. 2017, 96, 93-113. [CrossRef]

23. Diodato, D.; Weterings, A.B. The resilience of regional labour markets to economic shocks: Exploring the role of interactions among firms and workers. J. Econ. Geogr. 2014, 15, 723-742. [CrossRef]

24. Kitsos, A.; Bishop, P. Economic resilience in Great Britain: The crisis impact and its determining factors for local authority districts. Ann. Reg. Sci. 2018, 60, 329-347. [CrossRef] 
25. Lee, N. Grim down South? The determinants of unemployment increases in British cities in the 2008-2009 recession. Reg. Stud. 2014, 48, 1761-1778. [CrossRef]

26. Martin, R.; Sunley, P.; Gardiner, B.; Tyler, P. How regions react to recessions: Resilience and the role of economic structure. Reg. Stud. 2016, 50, 561-585. [CrossRef]

27. Huggins, R.; Thompson, P. Local entrepreneurial resilience and culture: The role of social values in fostering economic recovery. Camb. J. Reg. 2015, 8, 313-330. [CrossRef]

28. Clark, J.; Huang, H.I.; Walsh, J.P. A typology of 'innovation districts': What it means for regional resilience. Camb. J. Reg. 2010, 3, 121-137. [CrossRef]

29. Andres, L.; Round, J. The creative economy in a context of transition: A review of the mechanisms of micro-resilience. Cities 2015, 45, 1-6. [CrossRef]

30. Tubadji, A.; Nijkamp, P.; Angelis, V. Cultural hysteresis, entrepreneurship and economic crisis: An analysis of buffers to unemployment after economic shocks. Camb. J. Reg. 2016, 9, 103-136. [CrossRef]

31. Williams, N.; Vorley, T. Economic resilience and entrepreneurship: Lessons from the Sheffield City Region. Entrep. Reg. Dev. 2014, 26, 257-281. [CrossRef]

32. Vanolo, A. The Fordist city and the creative city: Evolution and resilience in Turin, Italy. City 2015, 6, 69-74. [CrossRef]

33. Kitsos, A.; Carrascal-Incera, A.; Ortega-Argilés, R. The role of embeddedness on regional economic resilience: Evidence from the UK. Sustainability 2019, 11, 3800. [CrossRef]

34. Bristow, G.; Healy, A. Regional resilience: An agency perspective. Reg. Stud. 2014, 48, 923-935. [CrossRef]

35. Martin, R. Regional economic resilience, hysteresis and recessionary shocks. J. Econ. Geogr. 2012, 12, 1-32. [CrossRef]

36. Kluge, J. Sectoral diversification as insurance against economic instability. J. Reg. Sci. 2017, 23, 1-20. [CrossRef]

37. Di Caro, P. Recessions, recoveries and regional resilience: Evidence on Italy. Camb. J. Reg. 2015, 8, $273-291$. [CrossRef]

38. Conroy, M.E. The concept and measurement of regional industrial diversification. South. Econ. J. 1975, 41, 492-505. [CrossRef]

39. Davies, A.; Tonts, M. Economic diversity and regional socioeconomic performance: An empirical analysis of the Western Australian grain belt. Geogr. Res. 2010, 48, 223-234. [CrossRef]

40. Dong, X.; Song, S.; Zhu, H. Industrial structure and economic fluctuation: Evidence from China. Soc. Sci. J. 2011, 48, 468-477. [CrossRef]

41. Eggers, A.; Ioannides, Y.M. The role of output composition in the stabilization of US output growth. J. Macroecon. 2006, 28, 585-595. [CrossRef]

42. Sherwood-Call, C. Assessing regional economic stability: A portfolio approach. Fed. Reserve Bank San Franc. Econ. Rev. 1990, 1, 17-26.

43. Kort, J.R. Regional economic instability and industrial diversification in the US. Land Econ. 1981, 57, 596-608. [CrossRef]

44. Attaran, M. Industrial diversity and economic performance in US areas. Ann. Reg. Sci. 1986, 20, 44-54. [CrossRef]

45. Jackson, R.W. An evaluation of alternative measures of regional industrial diversification. Reg. Stud. 1984, 18, 103-112. [CrossRef]

46. Doran, J.; Fingleton, B. US metropolitan area resilience: Insights from dynamic spatial panel estimation. Environ. Plan. A Econ. Space 2018, 50, 111-132. [CrossRef]

47. Evans, R.; Karecha, J. Staying on top: Why is Munich so resilient and successful? Eur. Plan. Stud. 2014, 22, 1259-1279. [CrossRef]

48. Dissart, J.C. Regional economic diversity and regional economic stability: Research results and agenda. Int. Reg. Sci. Rev. 2003, 26, 423-446. [CrossRef]

49. Siegel, P.B.; Alwang, J.; Johnson, T.G. Toward an improved portfolio variance measure of regional economic stability. Rev. Reg. Stud. 1994, 24, 71-86.

50. Simmie, J.; Martin, R. The economic resilience of regions: Towards an evolutionary approach. Camb. J. Reg. 2010, 3, 27-43. [CrossRef]

51. Shaw, K.; Maythorne, L. Managing for local resilience: Towards a strategic approach. Public Policy Adm. 2013, 28, 43-65. [CrossRef] 
52. Knight, J.; Xue, J. How high is urban unemployment in China? J. Chin. Econ. Bus. Stud. 2006, 4, 91-107. [CrossRef]

53. Fan, J.P.; Lang, L.H. The measurement of relatedness: An application to corporate diversification. J. Bus. 2000, 73, 629-660. [CrossRef]

54. Razzak, W. The Hodrick-Prescott technique: A smoother versus a filter: An application to New Zealand GDP. Econ. Lett. 1997, 57, 163-168. [CrossRef]

55. Hodrick, R.J.; Prescott, E.C. Postwar US business cycles: An empirical investigation. J. Money Credit Bank. 1997, 29, 1-16. [CrossRef]

56. National Bureau of Statistics of China. 60 Years of New China; China National Bureau of Statistics: Beijing, China, 2009.

57. National Bureau of Statistics of China. China Compendium of Statistics 1949-2008; China National Bureau of Statistics: Beijing, China, 2010.

58. Lütkepohl, H. New Introduction to Multiple Time Series Analysis; Springer Science \& Business Media: Berlin/Heidelberg, Germany, 2005.

59. Liu, Y. The dynamics of local upgrading in globalizing latecomer regions: A geographical analysis. Reg. Stud. 2017, 51, 880-893. [CrossRef]

60. National Bureau of Statistics of China. China Statistical Yearbook 2017; China Statistical Press: Beijing, China, 2017.

61. Lin, G.C.; He, C.; Li, X.; Wu, Y. Empowering regional economy with a spectacular space: Mega-events, over-drafted capital and momentary growth in China's metropolises. Area Dev. Policy 2018, 3, $24-41$. [CrossRef]

(C) 2019 by the authors. Licensee MDPI, Basel, Switzerland. This article is an open access article distributed under the terms and conditions of the Creative Commons Attribution (CC BY) license (http://creativecommons.org/licenses/by/4.0/). 